\title{
Light during darkness and cancer: relationships in circadian photoreception and tumor biology
}

\author{
Samar A. Jasser \\ Thomas Jefferson University \\ David E. Blask \\ Basset Research Institute \\ George C. Brainard \\ Thomas Jefferson University
}

Follow this and additional works at: https://jdc.jefferson.edu/neurologyfp

Part of the Neurology Commons

Let us know how access to this document benefits you

\section{Recommended Citation}

Jasser, Samar A.; Blask, David E.; and Brainard, George C., "Light during darkness and cancer: relationships in circadian photoreception and tumor biology" (2006). Department of Neurology Faculty Papers. Paper 1.

https://jdc.jefferson.edu/neurologyfp/1

This Article is brought to you for free and open access by the Jefferson Digital Commons. The Jefferson Digital Commons is a service of Thomas Jefferson University's Center for Teaching and Learning (CTL). The Commons is a showcase for Jefferson books and journals, peer-reviewed scholarly publications, unique historical collections from the University archives, and teaching tools. The Jefferson Digital Commons allows researchers and interested readers anywhere in the world to learn about and keep up to date with Jefferson scholarship. This article has been accepted for inclusion in Department of Neurology Faculty Papers by an authorized administrator of the Jefferson Digital Commons. For more information, please contact: JeffersonDigitalCommons@jefferson.edu. 


\title{
Light During Darkness and Cancer: Relationships in Circadian Photoreception and Tumor Biology
}

Samar A. Jasser ${ }^{1}$, David E. Blask ${ }^{2}$ and George C. Brainard ${ }^{1}$

(1) Department of Neurology, Light Research Program, Thomas Jefferson University, 1025 Walnut Street, Suite 507, PA 19107 Philadelphia, USA

(2) Laboratory of Chrono-Neuroendocrine Oncology, Bassett Research Institute, NY, USA

Corresponding author:

Samar A. Jasser

Email: samar.jasser@jefferson.edu

Phone: 215-955-9409

Fax: 215-923-7588

\begin{abstract}
The relationship between circadian phototransduction and circadian-regulated processes is poorly understood. Melatonin, commonly a circadian phase marker, may play a direct role in a myriad of physiologic processes. The circadian rhythm for pineal melatonin secretion is regulated by the hypothalamic suprachiasmatic nucleus (SCN). Its neural source of light input is a unique subset of intrinsically photosensitive retinal ganglion cells expressing melanopsin, the primary circadian photopigment in rodents and primates. Action spectra of melatonin suppression by light have shown that light in the 446$477 \mathrm{~nm}$ range, distinct from the visual system's peak sensitivity, is optimal for stimulating the human circadian system. Breast cancer is the oncological disease entity whose relationship to circadian rhythm fluctuations has perhaps been most extensively studied. Empirical data has increasingly supported the hypothesis that higher risk of breast cancer in industrialized countries is partly due to increased exposure to light at night. Studies of tumor biology implicate melatonin as a potential mediator of this effect. Yet, causality between lifestyle factors and circadian tumor biology remains elusive and likely reflects significant variability with physiologic context. Continued rigorous empirical inquiry into the physiology and clinical implications of these habitual, integrated aspects of life is highly warranted at this time.
\end{abstract}

\section{Introduction}

The relationship between circadian phototransduction, endogenous melatonin levels, endocrine hormone physiology, and the myriad of normal and pathological circadianregulated processes is far from being fully illuminated ${ }^{1,2}$. Many mutually consistent associations have been made between the light exposure history of an organism, circadian clock gene regulation, melatonin secretion, and the dysregulation of cell biology in cancer $^{1,3}$, but the specifics of these relationships are still poorly understood. It is well established that light of sufficient intensity has an acute suppressive effect upon the 
secretion of melatonin from the human pineal gland and that this suppression directly reflects the action of a non-visual photoreceptive system in circadian phototransduction ${ }^{4}$. The health implications of this suppressive potential of light upon melatonin, however, have only recently begun to be addressed.

Melatonin has been used frequently as a scientific marker of circadian phase ${ }^{5}$, or a biochemical marker of darkness ${ }^{6}$. Nevertheless, there is accumulating evidence that melatonin, as related to sleep/wake cycles and circadian physiology in general, may have a more direct role in several physiologic processes, spanning the fields of psychiatry, psychoneuroimmunology, oncology, and reproductive endocrinology ${ }^{7}$. For example, melatonin and circadian disturbance have been implicated in the pathophysiology of Seasonal Affective Disorder (SAD) ${ }^{7-10}$, and light therapy has been shown to be an effective treatment for this syndrome ${ }^{11-13}$. Low serum melatonin concentrations and urinary metabolite levels have also been found in women with estrogen-receptor positive breast cancer and men with prostate cancer ${ }^{14-16}$. More specifically, melatonin has been shown to have antiproliferative effects on neoplasms of several tissue types in vitro and in vivo ${ }^{17,18}$, to possess related antioxidant effects ${ }^{7,19-21}$, and to have immunostimulatory effects $^{7,22}$.

Relatedly, some evidence suggests that alterations to endogenous reproductive hormone physiology, particularly the menstrual cycle length, may be a common pathway through which disruptions to melatonin and circadian rhythms affect breast cancer development and progression ${ }^{23}$. Animal studies have demonstrated that melatonin can, via influence upon gonadotropin-releasing hormone $(\mathrm{GnRH})$ release in the hypothalamic-pituitary axis, affect gonadotropin ( $\mathrm{LH}$ and FSH) release from the pituitary gland and, in turn, gonadal function. There is some indirect evidence in humans consistent with these findings, though the implications are still quite unclear ${ }^{21,24}$. For example, a correlation has been made between the stage of breast cancer and inversely proportional changes in nocturnal melatonin levels in breast cancer patients ${ }^{15}$. One study showed that the addition of melatonin to the traditional pharmacologic management of metastatic breast cancer appeared to slow disease progression ${ }^{21,25}$. Consistent findings have been shown in other cancer types $^{21,26-27}$. Additionally, the oncostatic action of melatonin on human breast cancer has been linked to estrogen response ${ }^{21,28}$, with interactions occurring between melatonin and estradiol to influence breast cancer cell development ${ }^{21,29}$. This relationship between the hormones does not appear to be reciprocal, however, as it has been shown that the menstrual cycle phase and reproductive hormone status does not affect a woman's melatonin secretion ${ }^{7}$ or sensitivity to melatonin suppression by light ${ }^{30}$.

The complexity and importance of the interactions between light, the circadian system, and subsequent disturbances in hormone physiology and cancer is highlighted by the body of scientific evidence surrounding the relationship between light and breast cancer. Tissue-specific circadian clock organization in both normal and neoplastic proliferative tissue has the potential to accelerate tumor growth ${ }^{31}$. Similarly, the direction of melatonin rhythm entrainment to light stimuli as an advance or delay of the nighttime peak, is dependent upon the circadian time of the endogenous rhythm upon which the stimulus is superimposed $^{32}$. This plasticity of response, however, like every other dynamic

Published in Cancer Causes and Control, 17(4): 515-523, May 2006. The original article is available at http://www.springerlink.com/link.asp?id=m0231756036666x5. Copyright retained by Springer, Inc. 
physiologic process that occurs within the context of changing internal and external biological environments, is likely compounded by unique variations in response at different points along the pathways of light transmission. The concept of tissue-specific circadian programming via varied expression of clock genes is one mechanism of this plasticity, for example ${ }^{1}$. Regardless, any effort to begin clarifying this complexity is dependent upon an understanding of the incipient alterations that occur in the biological response to light, specifically, in circadian phototransduction.

\section{The first dominos in the biological effect of light}

The circadian rhythm for melatonin secretion is regulated by the endogenously generated rhythm of the hypothalamic suprachiasmatic nuclei ( $\mathrm{SCN})$, via an indirect multi-synaptic pathway to the pineal gland. This intrinsic rhythm is, in turn, synchronized by light input from the environment to the $\mathrm{SCN}$ via the direct projections of the retinohypothalamic tract $(\mathrm{RHT})^{33}$. A simplified diagram of the elements of this circuitry is shown in Figure 1. The source of these projections to the SCN is a unique subset of intrinsically photosensitive retinal ganglion cells (ipRGCs) ${ }^{34-37}$, and these intrinsically photosensitive ganglion cells have been shown to be in the same subset of retinal cells that express melanop $\sin ^{38-39}$.

Initially, the search for an alternate circadian photoreceptor included both opsin-based molecules such as RPE-retinal G protein-coupled receptor, peropsin, encephalopsin, and melanopsin as well as non-opsin molecules like cryptochrome ${ }^{40}$. Cryptochrome was an early candidate as a nonvisual photoreceptor in mammals since it plays a central role in circadian photoreception in lower species ${ }^{41}$. Current evidence, however, suggests that the two cryptochrome homologs found in the inner retina of mammals are not strictly required for mammalian circadian phototransduction, but may have an accessory function in inner retinal phototransduction ${ }^{42}$. 


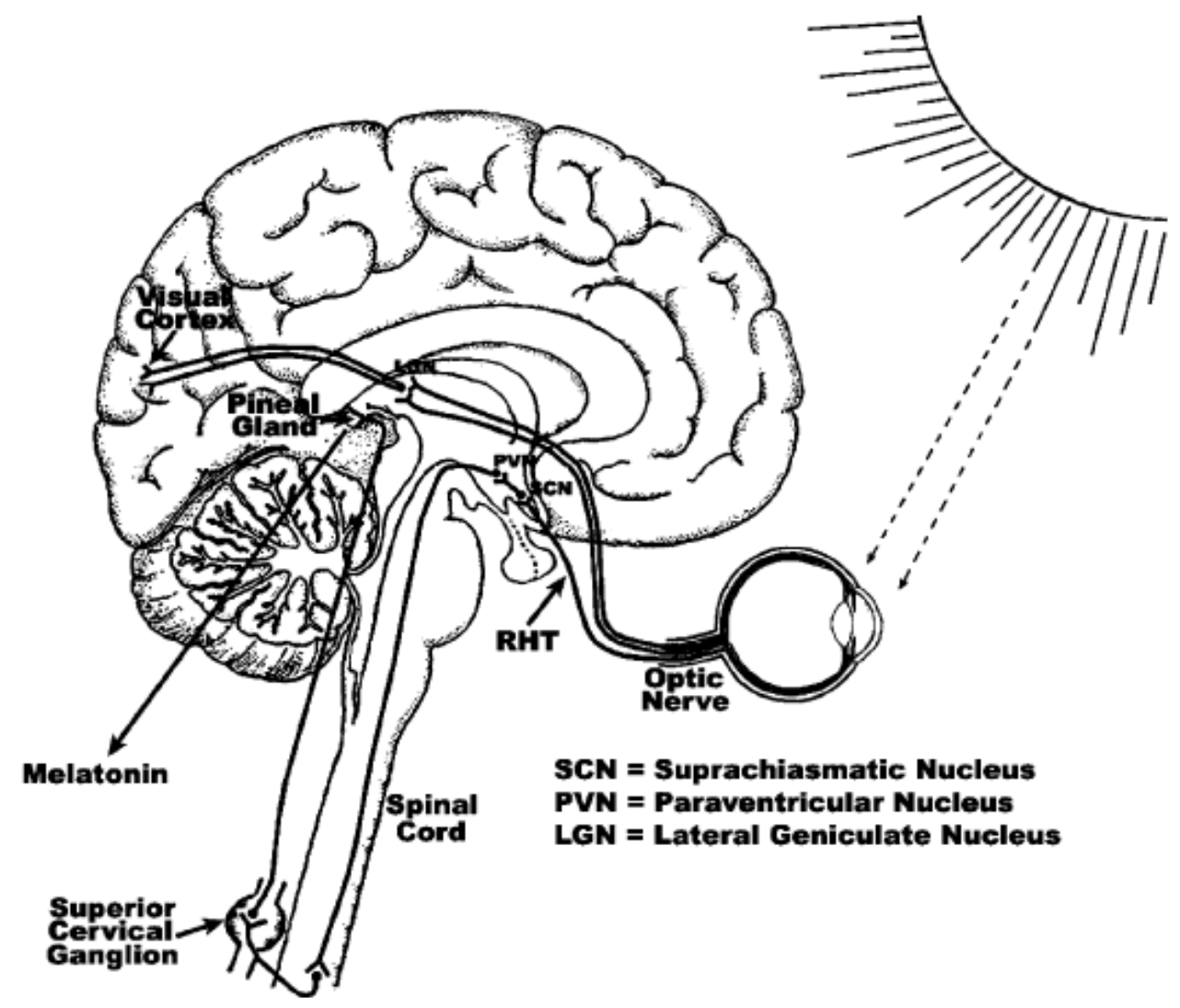

Fig. 1 Light influences melatonin secretion from the pineal gland via a multi-synaptic, indirect neural circuit. Light enters the eye through the pupillary aperture, stimulates the retina and sends its signal to the circadian pacemaker, the SCN, via a direct retinohypothalamic projection (RHT). Not shown here is the accessory connection between an integrating center in the thalamus, the intergeniculate leaflet (IGL), and the SCN. The IGL provides a second neural pathway for light to influence the circadian pacemaker. From the SCN, impulses travel to the pineal gland by first synapsing at the paraventricular nucleus of the hypothalamus, descending to synapse in the interomediolateral cell column (IMLCC) of the upper thoracic spinal cord, projecting to the superior cervical ganglion, and finally ascending along the cerebral vasculature to its final synapse at the pineal gland ${ }^{33}$

Recent evidence has confirmed that melanopsin is a primary photopigment mediating circadian phototransduction in rodents and primates ${ }^{43-46}$. Specifically, cells which are inherently incapable of photoreception were rendered photoreceptive after heterologous expression of human melanopsin ${ }^{43-46}$. It has been shown that the ipRGCs in rats and monkeys will depolarize in response to light with a peak spectral sensitivity around $480 \mathrm{~nm}$, even with the blockage of synaptic input from rods and cones ${ }^{34}$. Furthermore, studies in rodents with retinal degeneration have indicated that neither the rod nor cone photoreceptors necessarily participate in circadian responses to light, including melatonin suppression and photoperiodic respons $\mathrm{e}^{47-49}$. Thus, both the anatomical distribution and physiologic profile of melanopsin indicate that this photoreceptive system is a 
fundamental gateway for influencing the SCN's perception of light stimuli in the environment, and consequently, the responses of many dependent biological processes.

The acute suppression of plasma melatonin by light is a well-defined means of measuring the sensitivity of this non-visual photoreceptive system ${ }^{4,50}$, regardless of any downstream effects of the synthesized melatonin. Action spectra of melatonin suppression by light in healthy human subjects have shown that light in the $446-477 \mathrm{~nm}$ range is optimal for stimulating the circadian system and eliciting this suppression response ${ }^{51-52}$. This peak is distinct from the peak sensitivity of the three-cone photopic visual system, as well as each of the individual rods and cones for vision ${ }^{51-53}$. A study demonstrating that $460 \mathrm{~nm}$ monochromatic light is significantly more potent than $555 \mathrm{~nm}$ for phase-shifting the circadian pacemaker of healthy humans offers specific evidence to show that the peak sensitivity of the human circadian pacemaker is distinct from that of the classical threecone system for photopic vision ${ }^{54}$. Figure 2 illustrates the two distinct photosensitivity inputs for vision and melatonin suppression.

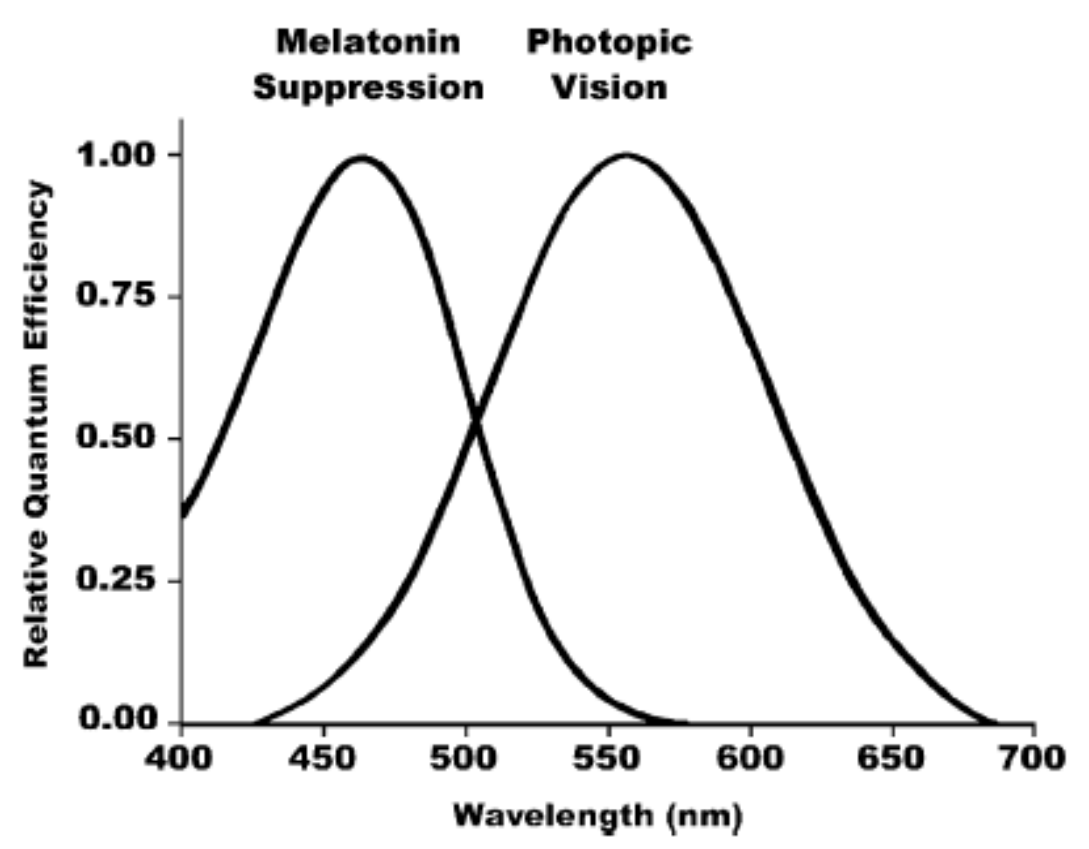

Fig. 2 Comparison of action spectra for the novel, melanopsin-based circadian photoreceptive system and the photopic, classical cone photoreceptors. The circadian action spectrum peaks in the $446-477 \mathrm{~nm}$ range, versus a $555 \mathrm{~nm}$ peak for the three cone visual system

Of note, however, it is apparent that the rods and cones, though not essential to the circadian response to light stimuli, appear to have a role in circadian photoreception under normal physiologic conditions. For example, retinally degenerate mice, while still maintaining the capacity for circadian photoreception and response to light, have a spectral sensitivity for circadian phase-shifting that is different from wild-type mice with normal functioning rods and cones ${ }^{55}$. There is also a residual phase shifting response in melanopsin genetic knock-out mice which suggests an alternate or redundant means for 
light input to the $\mathrm{SCN}^{56}$. Studies in transgenic rodent models suggest that rod and cone photoreceptors have the capacity to transduce light for circadian regulation ${ }^{57}$. The extent to which these basic molecular findings in other mammals can be carried over in application to humans is still unknown, however the evidence to date in humans and nonhuman primates suggests there is a high level of correlation ${ }^{39,46}$. For example, it has been shown in humans that there is a bidirectional, mutual input potential between the novel, non-classical opsin-based photopigment and the classical rod-cone photoreceptors, where, under normal conditions, the novel circadian photopigment has a measurable role in rod and cone adaptation to light over time ${ }^{58}$. The SCN, itself, is also capable of receiving integrated neural information from the intergeniculate leaflet (IGL) of the thalamus, which itself receives retinal projections from the rod and cone visual system ${ }^{59}$. Thus, light has at least two neural pathways for stimulating the SCN in the process of entrainment, phase-shifting, or melatonin suppression. The light-induced regulation of melatonin or the broader circadian system can, in turn, potentially alter other physiologic processes downstream to a degree of magnitude which is still unknown.

The distinction between visual and circadian photoreception has been demonstrated on an empiric level as well. Blind persons who have no residual perception of light stimuli have nonetheless shown a melatonin suppression and circadian phase-shifting responses to bright light exposure ${ }^{60-61}$. Similarly, colorblind individuals appear to maintain this lightinduced melatonin suppression ${ }^{62}$. The epidemiologic evidence showing a significantly decreased risk of breast cancer in women with profound bilateral blindness as compared with normally sighted women ${ }^{63-64}$ suggests a correlation between these findings and the oncostatic properties of melatonin in the setting of cancer. Also supporting the idea of circadian melatonin regulation via a non-visual photoreceptive system as an endocrine link between light and reproductive hormone disturbances is the finding that blindness in human females is associated with an age of menarche that is earlier than normal and proportional to the level of light perception loss ${ }^{65}$.

Finally, although less sensitive than the visual system, circadian photoreception appears to be capable of responding to relatively low levels of light ${ }^{4,5,66-6} 8$. It has been shown in laboratory animals that indirect light as $\operatorname{dim}$ as $0.2 \operatorname{lux}\left(0.06 \mu \mathrm{W} / \mathrm{cm}^{2}\right)$ has the capacity to significantly suppress nocturnal plasma melatonin levels and consequently increase hepatoma growth ${ }^{69-70}$. At the same time, however, circadian photoreception appears to involve a still poorly characterized and complicated method of integration of light stimuli over time by the photoreceptors themselves ${ }^{58}$, further downstream at the $\mathrm{SCN}^{71}$, and even more broadly on a tissue-specific level ${ }^{1}$. More recently, specific molecular findings are highly suggestive of melanopsin behaving more like an invertebrate opsin in nature than a vertebrate opsin and acting more like a photopigment than a photoisomerase influencing some other still-unknown opsin molecule ${ }^{58}$. The implications of these findings are far-reaching with regard to questions of photoreceptor adaptation and bleaching, for recent light history does appear to attenuate the response of subsequent melatonin suppression by bright white light ${ }^{72-73}$. Yet this varied circadian photoreceptive response throughout time cannot be accounted for by simple photon summation over the period of observation ${ }^{54}$. Summarily, it appears that circadian photoreception has specific spectral parameters for optimal response and a very low threshold for excitation, but

Published in Cancer Causes and Control, 17(4): 515-523, May 2006. The original article is available at http://www.springerlink.com/link.asp?id=m0231756036666x5. Copyright retained by Springer, Inc. 
these characteristics cannot be accurately considered in isolation from their environmental, biological, and behavioral context.

\section{Circadian light measurement}

With such a distinct photoresponse profile, it has become increasingly apparent that traditional means of light measurement do not suffice to provide an accurate point-intime measurement of light input to the mammalian circadian system. For more than 25 years, research surrounding human circadian physiology has primarily used a photometric-based description and light measurement system ${ }^{5,74}$. The use of this measurement perspective, however, implies that the human visual (rod and cone photoreceptor) system is the primary system involved in circadian photoreception. A series of recent human experiments employing standard photobiological techniques have shown, specifically, that lux measurements are inappropriate for circadian, neuroendocrine, and therapeutic purposes. Specifically, equal photon doses of shortwavelength monochromatic light evoke a stronger acute melatonin suppression responses, circadian phase-shifts, core body temperature changes, subjective sleepiness, heart rate, auditory reaction time, and auditory lapses in human subjects, when compared with longer wavelength light at the peak of the photopic sensitivity curve $\mathrm{e}^{51-54,75}$. The importance of this distinction in light measurement is demonstrated by the finding that, under optimum exposure conditions, as little as 5 lux of $460 \mathrm{~nm}$ light evokes an equivalent phase shift ( $3 \mathrm{~h}$ phase delay) when compared with 10,000 lux white fluorescent light ${ }^{54}$.

Thus, the characterization of light exposures for non-visual photobiological responses, including melatonin suppression, circadian phase-shifting, and tumor growth, should include radiometric quantification of irradiance and spectral power distribution ${ }^{76-77}$.

Furthermore, the implication of these findings for understanding the influence of various lighting conditions upon subsequent tumor development in vivo is to highlight the need for increased research conducted under conditions that emulate the daily photic environment of humans.

\section{The time of light}

The circadian system's sensitivity to light stimuli varies immensely with both the circadian phase and the end effect being measured. It has been shown that practically all normal proliferating tissues have been shown to undergo circadian variation in DNA synthesis and mitotic index across a $24 \mathrm{~h}$ period, and similar variations appear to exist in tumor tissues depending upon the type and stage of growth ${ }^{31,78}$. Furthermore, as indicated in Figure 3, this tissue-specific rhythm is not necessarily directly reflective of broader, overarching circadian rhythms regulated by the biological master clock in the $\mathrm{SCN}^{1}$. Many anticancer agents have limiting cytotoxic effects on normal tissues that vary with cell proliferative activity and cell cycle stage ${ }^{78}$. Thus, an understanding of the characteristics of this circadian variation in response to a given light stimulus is highly germane to clarifying the relationship between light and cancer. Gaining utility of this 
differential response of normal and neoplastic tissues to chemotherapy according to circadian state has the potential to maximize chemotherapeutic efficacy while minimizing toxicity. Advantages for circadian scheduling of chemotherapies have in fact already been shown to diminish side effects and increase the maximum tolerated doses for increased tumor response ${ }^{78}$.

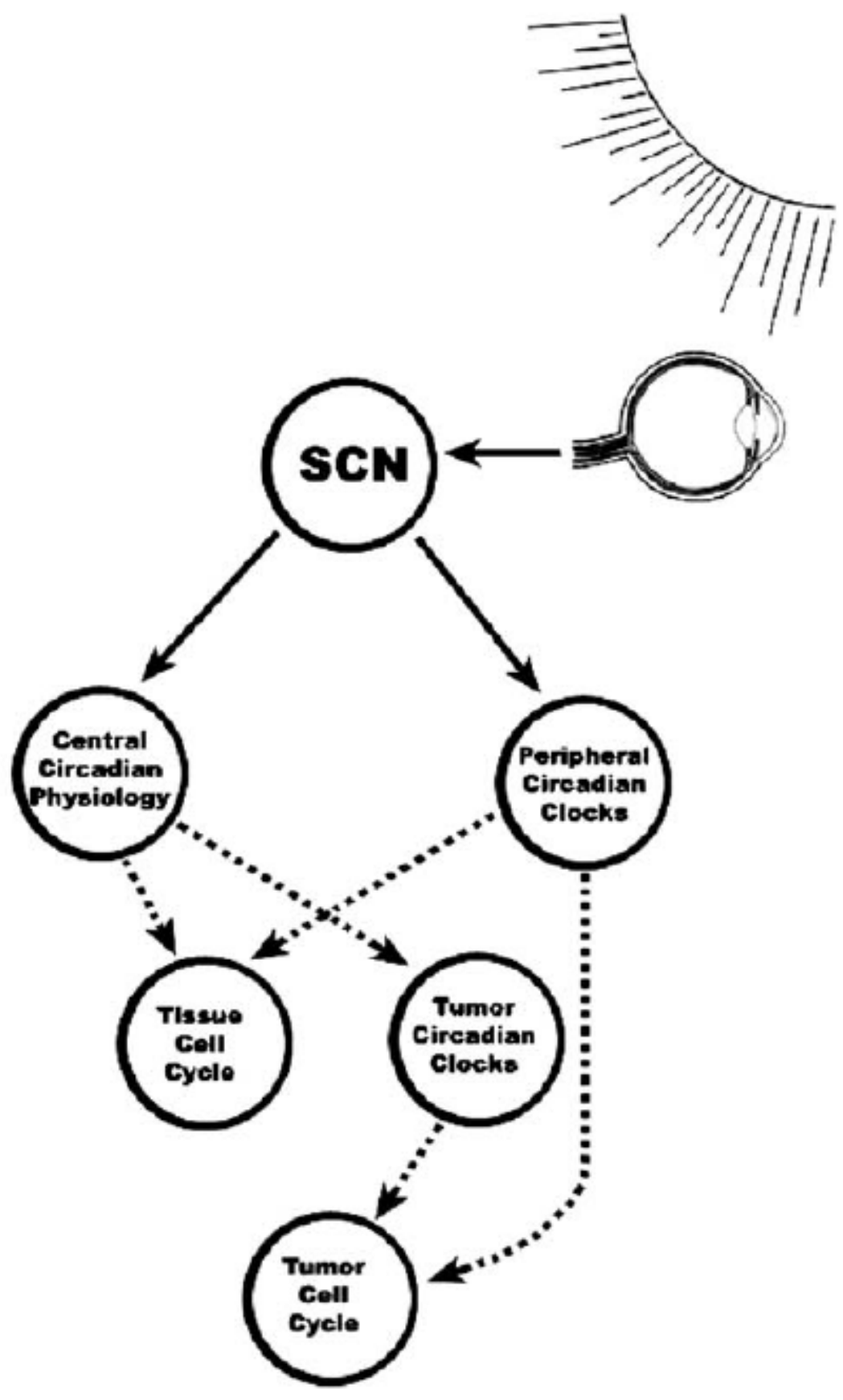

Fig. 3 Cell growth and division follows a tissue-specific program that is influenced by, but not homologous with, the SCN master clock rhythm. Solid arrows represent primary neural influence. Dotted arrows represent secondary synaptic influence. Figure adapted from Hastings, et al. ${ }^{1}$ 


\section{Light exposure during darkness and breast cancer}

Breast cancer is the oncological disease entity whose relationship to circadian rhythm fluctuations has been brought most extensively to the attention of both clinical and basic science research. It has been shown that otherwise healthy women who are chronically subjected to nighttime shiftwork, and thus to light exposure at night, have a higher incidence of breast cancer ${ }^{79-80}$. Epidemiologically, the World Health Organization estimated in 1980 that half of all cancer in the world occurred in areas comprising onefifth of the world's population, namely industrialized countries ${ }^{81}$. Thus, it has been hypothesized that the increased risk of breast cancer in industrialized countries is due, in part, to increased exposure to light at night, relative to unindustrialized countries who have significantly fewer nightshift workers ${ }^{23,82-83}$.

Increasingly, published empirical data has been supporting this hypothesis. Melatonin has been shown, at physiologic concentrations, to have a direct inhibitory effect on human breast cancer cells in vitro ${ }^{21}$ and even more recently, in vivo ${ }^{18,84}$. It has also been established that light of sufficient intensity at night has the capacity to acutely inhibit the normal nocturnal rise in melatonin in humans ${ }^{4,21,85}$. This, in turn, would suggest that any environmental exposure which results in a relative decrease in integrated melatonin levels over time would consequently result in less oncostatic protection and a higher rate of breast cancer development and/or proliferation. This theoretical construct is consistent with epidemiologic findings ${ }^{80}$, as well as the melatonin-breast cancer hypothesis ${ }^{82}$. With acute light-induced melatonin suppression, however, there is likely to be coincident disruption of circadian phase and/or entrainment. Thus, it has not yet been determined if light exposure at night is a risk specifically due to acute melatonin suppression, to circadian disruption, or both.

The majority of studies have demonstrated a marked stimulatory effect of either pinealectomy or constant light exposure on tumor development and growth ${ }^{21,86}$. In general, following pinealectomy or exposure to constant bright light, not only do tumors appear earlier, but a greater percentage of animals develop tumors and more tumors develop per animal as compared to control animals maintained on an alternating $12 \mathrm{~h}$ light:12 h dark cycle. Although constant light exposure seems to stimulate tumorigenesis in the majority of investigations, clearly one-third of the studies conducted report either inhibitory, mixed or no effects on the development of experimental cancer. Interestingly, more consistent stimulatory actions of continuous illumination appear to occur with respect to the growth of established tumors ${ }^{86}$. In rats bearing either tissue-isolated rat liver cancer (i.e., hepatoma) or rat mammary cancer, constant bright light exposure (i.e., 300 lux at eye level) for one week prior to tumor implantation and continuing thereafter, completely suppresses the nocturnal, circadian rise in circulating melatonin levels, as compared with L:D controls. Tumors appear much earlier as a result of constant light exposure and their average daily growth rate accelerates by a factor of 2.5-6 times over the average growth rate of tumors in the L:D control group. The marked increase in the rates of tumor growth results from a substantial augmentation in the rate of rumor uptake

Published in Cancer Causes and Control, 17(4): 515-523, May 2006. The original article is available at http://www.springerlink.com/link.asp?id=m0231756036666x5. Copyright retained by Springer, Inc. 
of linoleic acid (LA) and its conversion to 13-hydroxyoctadecadienoic acid (13-HODE) as a consequence of the suppression of the circadian melatonin signal ${ }^{69-70,87}$.

The ability of ocular light exposure to suppress pineal melatonin production depends on the intensity, wavelength, duration, and timing of light. As important as the constant bright light studies are, they address only one aspect of the intensity issue. Previous studies have demonstrated that the exposure of rats to low intensity fluorescent light (i.e., 0.2 lux at rodent eye level) during the dark phase for one week prior to the implantation of tissue-isolated rat hepatomas, results in a nearly complete suppression of circulating melatonin levels. Interestingly, the tumor growth rate, LA uptake, and metabolism to 13HODE are nearly as rapid as in constant light-exposed animals, indicating that low intensity light-induced melatonin suppression during the dark phase is as effective as constant light exposure in tumor growth and LA metabolism ${ }^{69-70}$. Even more recent studies have examined the effects of different light intensities during darkness on nocturnal circulating melatonin levels and the growth and LA metabolism of rat hepatoma $7288 \mathrm{CTC}^{88}$. Exposure of tumor-bearing rats to fluorescent light intensities (at rodent eye level) ranging from complete darkness to constant bright light $\left(345 \mu \mathrm{W} / \mathrm{cm}^{2}\right.$ or $\sim 840$ lux) results in a dose-dependent suppression of melatonin levels with a concomitant dose-related stimulation of tumor growth, LA uptake and 13-HODE production ${ }^{88}$. These findings represent the first evidence that stimulation of tumor growth and metabolism is dependent on the degree of the suppression of melatonin production that is, in turn, dependent upon the intensity of light present during darkness. Studies are currently examining fluence-response issues relative to melatonin suppression and the growth and LA metabolism of human breast cancer xenografts in nude rats. Furthermore, other ongoing studies are focusing on the role of the nocturnal, circadian melatonin signal, and its suppression by light during darkness in human volunteers, on human breast cancer xenograft growth and LA metabolism.

The light-melatonin-breast cancer hypothesis, with specific regard to human breast carcinogenesis, has not been directly addressed until recently. This has been done using a strain of athymic female rats in which human breast cancer xenografts grow quite well. During a two week period following their transfer from a 12L:12D light:dark cycle (i.e., intact circadian melatonin signal) to constant 300 lux bright light (i.e., no nocturnal melatonin signal), the average daily rate of tumor growth in constant light-exposed rats increased by seven-fold in comparison to the tumor growth rate in animals remaining on an L:D cycle. This accelerated rate of human breast cancer growth was initiated and sustained as a result of increases in the rate of tumor uptake of LA and its metabolism to 13-HODE. This augmented rate of tumor LA uptake and metabolism resulted from constant light-induced suppression of the circadian melatonin signal which normally drives the inhibition of these processes during the dark phase ${ }^{84}$. This is the first experimental evidence to date showing a link between inappropriate exposure to continuous bright light and increased growth and fatty acid metabolism of human breast cancer.

Thus, a better understanding of the photobiology underlying the effects of light upon endogenous melatonin rhythm offers potential to further scientific understanding of the 
development and maintenance of oncologic processes. More specifically, the response of this dynamic system to changes in light intensity, spectral quality, and varied light exposure history is highly germane to gaining a better understanding of the potential relationships between light exposure and cancer risk. Elucidating the underlying photic input physiology to the pineal gland and subsequent melatonin regulation may provide a common doorway to influence both normal neuroendocrine homeostasis as well as oncological processes. Ultimately, rationally integrated lifestyle approaches may one day be used to prevent the development of some breast cancers as well as to restore health in some cancer patients.

\section{Conclusion}

Concomitant molecular and empiric investigations of the relationship between light and cancer have begun to scratch the surface of this clinically expansive area of research. Still, clinical applications and shifts in theoretical structure are slow to follow scientific developments, and there is much room for future investigations to begin clarifying these ideas and give form to this promising evidence. For example, from a purely clinical perspective, etiologic theorizing concerning human breast cancer has centered primarily upon estrogen, its receptors, and the genetic inheritance of traits that influence their relationship. Currently, a patient's integrated estrogen exposure over time is perhaps one of the most exigently debated breast cancer risk factors. Accordingly, the personal historical elements which are most commonly analyzed in the primary survey of a patient's risk and/or prognosis for breast cancer include: age at onset of menarche and menopause, age of first term pregnancy and number of pregnancies, as well as personal and family history of pre-menopausal breast cancer ${ }^{89-91}$. In contrast, the patient's sleep/wake cycle, melatonin rhythm, light history, and work schedule are not typically considered as being relevant to this cancer risk assessment, in spite of the growing body of evidence supporting this possibility.

While accumulating evidence points toward potential for the various work schedule and lifestyle factors to influence tumorigenesis and progression, causality remains elusive and likely reflects significant variability with physiologic context. For example, it seems that the pathway by which melatonin influences tumor development and progression is dependent upon fatty acid availability and metabolism ${ }^{18,70}$. High fat consumption has not been consistently correlated with an increased risk of breast cancer in humans ${ }^{92}$, but increased constitutional fat content in obese females is correlated with higher levels of endogenous estrogen, which may, in turn, be the effector that potentiates many gynecologic neoplasms, such as breast cancer ${ }^{93}$. Furthermore, dietary constituents have been correlated with increased risk of other cancers, but the molecular players within this risk are yet to be consistently identified ${ }^{92,94}$.

Light exposure, the status of physiologic circadian rhythms, diet ${ }^{95}$, and exercise habits ${ }^{95}$, though recognized as bearing a potential influence on cancer outcome, are less welldefined in their roles in cancer pathophysiology and are consequently often given subordinate attention in clinical approaches to cancer ${ }^{96}$. Continued rigorous empirical inquiry into the physiology and clinical implications of these habitual, integrated aspects 
of life is highly warranted at this time. Ultimately, when the weight of evidence becomes compelling, the traditions of clinical practice will be adjusted to reflect the relationship between light and cancer that current evidence suggests.

Acknowledgments The authors appreciate the continuing support and assistance of John P. Hanifin in referencing and reviewing the manuscript. Primary support for this manuscript was provided by grants from NIEHS IR21ES11659, with valuable co-support from NCI 1RO1CA85408-01A2.

\section{References}

1. Hastings MH, Reddy AB, Maywood ES (2003) A clockwork web: circadian timing in brain and periphery, in health and disease. Nat Rev Neurosci 4:649-661

2. Refinetti R (2000) Circadian Physiology. CRC Press, Boca Raton, Florida, 1-184

3. Stevens RG, Wilson BW, Anderson LE (eds) (1997) The Melatonin Hypothesis: Breast Cancer and Use of Electric Power. Columbus, Battelle Press, Ohio, pp 1760

4. Brainard GC, Rollag MD, Hanifin JP (1997) Photic regulation of melatonin in humans: ocular and neural signal transduction. J Biol Rhythms 12:537-546

5. Brainard GC, Hanifin JP (2005) Photons, clocks and consciousness. J Biol Rhythms 20:314-325

6. Reiter RJ, (1991) Pineal melatonin: cell biology of its synthesis and of its physiological interactions. Endocr Rev 12:151-180

7. Brzezinski A, (1997) Melatonin in humans. N Engl J Med 336:186-195

8. Lewy AJ, Sack RL, Miller LS, Hoban TM (1987) Antidepressant and circadian phase-shifting effects of light. Science 235:352-354

9. Lewy AJ, Bauer VK, Cutler NL, et al. (1998) Morning vs evening light treatment of patients with winter depression. Arch Gen Psychiatry 55:890-896

10. Terman JS, Terman M, Lo ES, Cooper TB (2001) Circadian time of morning light administration and therapeutic response in winter depression. Arch Gen Psychiatry 58:69-75

11. Lam RW (ed.) (1998) Seasonal Affective Disorder and Beyond: Light Treatment for SAD and Non-SAD Disorders. American Psychiatric Press, Washington, D.C., pp 1-327

12. Terman M, Terman JS, Ross DC (1998) A controlled trial of timed bright light and negative air ionization for treatment of winter depression. Arch Gen Psychiatry 55:875-882

13. Eastman CI, Young MA, Fogg LF, Liu L, Meaden PM (1998) Bright light treatment of winter depression: a placebo-controlled trial. Arch Gen Psychiatry 55:883-889

14. Tamarkin L, Danforth D, Lichter A, et al. (1982) Decreased nocturnal plasma melatonin peak in patients with estrogen receptor positive breast cancer. Science 216:1003-1005

15. Bartsch C, Bartsch H, Fuchs U, Lippert TH, Bellman O, Gupta D (1989) Stagedependent depression of melatonin in patients with primary breast cancer. Cancer 64:426-433 
16. Bartsch C, Bartsch H, Schmidt A, Ilg S, Bichler KH, Fluchter SH (1992) Melatonin and 6-sulfatoxymelatonin circadian rhythms in serum and urine or primary prostrate cancer patients: evidence for reduced pineal activity and relevance of urinary determinations. Clin Chim Acta 209:153-167

17. Blask DE (1984) The pineal: an oncostatic gland? In: Reiter RJ (ed.) The Pineal Gland. Raven Press, New York, 253-284

18. Blask DE, Sauer LA, Dauchy RT, Holowachuk EW, Ruhoff MS, Kopff HE (1999) Melatonin inhibition of cancer growth in vivo involves suppression of tumor fatty acid metabolism via melatonin receptor-mediated signal transduction events. Cancer Res 59:4693-4701

19. Reiter RJ (1994) Melatonin: multifaceted messenger to the masses. Lab Med 25:438-443

20. Cos S, BlaskDE(1994) Melatonin modulates growth factor activity in MCF-7 human breast cancer cells. J Pineal Res 17:25-32

21. Blask DE, Sauer LA, Dauchy RT (2002) Melatonin as a chronobiotic/anticancer agent: cellular, biochemical, and molecular

1. mechanisms of action and their implications for circadian-based cancer therapy. Curr Top Med Chem 2:113-132

22. Panzer A, Viljoen M (1997) The validity of melatonin as an oncostatic agent. J Pineal Res 22:184-202

23. Stevens RG, Rea MS (2001) Light in the built environment: potential role of circadian disruption in endocrine disruption and breast cancer. Cancer Causes Control 12:279-287

24. Stevens RG (2001) Circadian disruption and breast cancer. In: Bartsch C, Bartsch H, Blask DE, Cardinali DP, Hrushesky WJM, Mecke D (eds) The Pineal Gland and Cancer: Neuroendocrine Mechanisms in Malignancy. Springer-Verlag, Berlin, 511-517

25. Lissoni P, Barni S, Meregalli S, et al. (1995) Modulation of cancer endocrine therapy by melatonin: a phase II study of tamoxifen plus melatonin in metastatic breast cancer patients progressing under tamoxifen alone. Br J Cancer 71:854 856

26. Lissoni P, Meregalli S, Nosetto L, et al. (1996) Increased survival time in brain glioblastomas by a radioneuroendocrine strategy with radiotherapy plus melatonin compared to radiotherapy alone. Oncology 53:43-46

27. Gonzalez R, Sanchez A, Ferguson JA, et al. (1991) Melatonin therapy of advanced human malignant melanoma. Melanoma Res 1:237-243

28. Hill SM, Spriggs LL, Simon MA, Muraoka H, Blask DE (1992) The growth inhibitory action of melatonin on human breast cancer cells is linked to the estrogen response system. Cancer Lett 64:249-256

29. Crespo D, Fernandez-Viadero C, Verduga R, Ovejero V, Cos S (1994) Interaction between melatonin and estradiol on morphological and morphometric features of MCF-7 human breast cancer cells. J Pineal Res 16:215-222

30. Nathan PJ, Norman TR, Burrows GD (1999) Effect of menstrual cycle stage on the melatonin suppression by dim white light. Psychoneuroendocrinology 24:193-200 
31. Filipski E, Delaunay F, King VM, et al. (2004) Effects of chronic jet lag on tumor progression in mice. Cancer Res 64:7879-7885

32. Lewy AJ, Sack RA, Singer CL (1984) Assessment and treatment of chronobiologic disorders using plasma melatonin levels and bright light exposure: the clock-gate model and the phase response curve. Psychopharmacol Bull 20:561-565

33. Klein DC, Moore RY, Reppert SM (eds) (1991) Suprachiasmatic Nucleus: The Mind's Clock. Oxford University Press, Oxford, pp 5-456

34. Berson DM, Dunn FA, Takao M (2002) Phototransduction by retinal ganglion cells that set the circadian clock. Science 295:1070-1073

35. Berson DM (2003) Strange vision: ganglion cells as circadian photoreceptors. Trends Neurosci 26:314-320

36. Provencio I, Rollag MD, Castrucci AM (2002) Photoreceptive net in the mammalian retina. Nature 415:493

37. Gooley JJ, Lu J, Fischer D, Saper CB (2003) A broad role for melanopsin in nonvisual photoreception. J Neurosci 23:7093-7106

38. Provencio I, Rodriguez IR, Jiang G, Hayes WP, Moreira EF, Rollag MD (2000) A novel human opsin in the inner retina. J Neurosci 20:600-605

39. Hannibal J, Hindersson P, Ostergaard J, et al. (2004) Melanopsin is expressed in PACAP-containing retinal ganglion cells of the human retinohypothalamic tract. Invest Ophthalmol Vis Sci 45:4202-4209

40. Kumbalasiri T, Provencio I (2005) Melanopsin and other novel mammalian opsins. Exp Eye Res 81:368-375

41. Partch CL, Sancar A (2005) Cryptochromes and circadian photoreception in animals. Methods Enzymol 393:726-745

42. Van Gelder RN (2005) Nonvisual ocular photoreception in the mammal. Methods Enzymol 393:746-755

43. Melyan Z, Tarttelin EE, Bellingham J, Lucas RJ, Hankins MW (2005) Addition of human melanopsin renders mammalian cells photoresponsive. Nature 433:741745

44. Qiu X, Kumbalasiri T, Carlson SM, et al. (2005) Induction of photosensitivity by heterologous expression of melanopsin. Nature 433:745-749

45. Panda S, Nayak SK, Campo B, Walker JR, Hogenesch JB, Jegla T (2005) Illumination of melanopsins signaling pathway. Science 307:600-604

46. Dacey DM, Liao H-W, Peterson BB, et al. (2005) Melanopsinexpressing ganglion cells in primate retina signal colour and irradiance and project to the LGN. Nature 433:749-754

47. Pevet P, Heth G, Hiam A, Nevo E (1984) Photoperiod perception in the blind mole rat (Spalax ehrenbergi, Nehring): involvement of the Harderian gland, atrophied eyes, and melatonin. J Exp Zool 232:41-50

48. Webb SM, Champney TH, Lewinski AK, Reiter RJ (1985) Photoreceptor damage and eye pigmentation: influence on the sensitivity of rat pineal $\mathrm{N}$ acetyltransferase activity and melatonin levels to light at night. Neuroendocrinology 40:205-209 
49. Foster RG, Provencio I, Hudson D, Fiske S, DeGrip W, Menaker M (1991) Circadian photoreception in the retinally degenerate mouse (rd/rd). J Comp Physiol [A] 169:39-50

50. Arendt J (1998) Melatonin and the pineal gland: influence on mammalian seasonal and circadian physiology. Rev Reprod 3:13-22

51. Brainard GC, Hanifin JP, Greeson JM, et al. (2001) Action spectrum for melatonin regulation in humans: evidence for a novel circadian photoreceptor. $\mathrm{J}$ Neurosci 21:6405-6412

52. Thapan K, Arendt J, Skene DJ (2001) An action spectrum for melatonin suppression: evidence for a novel non-rod, non-cone photoreceptor system in humans. J Physiol 535:261-267

53. Brainard GC, Hanifin JP, Rollag MD, et al. (2001) Human melatonin regulation is not mediated by the three cone photopic visual system. J Clin Endocrinol Metab $86: 433-436$

54. Lockley SW, Brainard GC, Czeisler CA (2003) High sensitivity of the human circadian melatonin rhythm to resetting by short wavelength light. J Clin Endocrinol Metab 88: 4502-4505

55. Yoshimura T, Ebihara S (1996) Spectral sensitivity of photoreceptors mediating phase-shifts of circadian rhythms in retinally degenerate $\mathrm{CBA} / \mathrm{J}(\mathrm{rd} / \mathrm{rd})$ and normal CBA/N (+/+) mice. J Comp Physiol [A] 178:797-802

56. Ruby N, Brennan T, Xie X, et al. (2002) Role of melanopsin in circadian responses to light. Science 298:2211-2213

57. Panda S, Sato TK, Castrucci AM, et al. (2002) Melanopsin (Opn4) requirement for normal light-induced circadian phaseshifting. Science 298:2213-2216

58. Hankins MW, Lucas RJ (2002) The primary visual pathway in humans is regulated according to long-term light exposure through the action of a nonclassical photopigment. Curr Biol 12:191-198

59. Morin LP, Blanchard JH, Provencio I (2003) Retinal ganglion cell projections to the hamster suprachiasmatic nucleus, intergeniculate leaflet, and visual midbrain: bifurcation and melanopsin immunoreactivity. J Comp Neurol 465:401-416

60. Czeisler CA, Shanahan TL, Klerman EB, et al. (1995) Suppression of melatonin secretion in some blind patients by exposure to bright light. N Engl J Med 332:611

61. Klerman EB, Shanahan TL, Brotman DJ, et al. (2002) Photic resetting of the human circadian pacemaker in the absence of conscious vision. J Biol Rhythms 17:548-555

62. Ruberg FL, Skene DJ, Hanifin JP, et al. (1996) Melatonin regulation in humans with color vision deficiencies. J Clin Endocrinol Metab 81:2980-2985

63. Hahn RA (1991) Profound bilateral blindness and the incidence of breast cancer. Epidemiology 2:208-210

64. Feychting M, Osterlund B, Ahlbom A (1998) Reduced cancer incidence among the blind Epidemiology 9:490-494

65. Zacharias L, Wurtman RJ (1964) Blindness: its relation to the age of menarche. Science 144:1154-1155 
66. Brainard GC, Lewy AJ, Menaker M, et al. (1988) Dose-response relationship between light irradiance and the suppression of melatonin in human volunteers. Brain Res 454:212-218

67. Glickman G, Levin R, Brainard GC (2002) Ocular input for human melatonin regulation: relevance to breast cancer. Neuroendocrinol Lett 23:17-22

68. Zeitzer JM, Dijk D-J, Kronauer RE, Brown EN, Czeisler CA (2000) Sensitivity of the human circadian pacemaker to nocturnal light: melatonin phase resetting and suppression. J Physiol 526: 695-702

69. Dauchy RT, Sauer LA, Blask DE, Vaughan GM (1997) Light contamination during the dark phase in "photoperiodically controlled" animal rooms: effect on tumor growth and metabolism in rats. Lab Anim Sci 47:511-518

70. Dauchy RT, Blask DE, Sauer LA, Brainard GC, Krause JA (1999) Dim light during darkness stimulates tumor progression by enhancing tumor fatty acid uptake and metabolism. Cancer Lett 144:131-136

71. Aggelopoulos NC, Meissl H (2000) Responses of neurones of the rat suprachiasmatic nucleus to retinal illumination under photopic and scotopic conditions. J Physiol 523:211-222

72. Smith KA, Schoen MW, Czeisler CA (2004) Adaptation of human pineal melatonin suppression by recent photic history. J Clin Endocrinol Metab 89:3610-3614

73. Hebert M, Martin SK, Lee C, Eastman CI (2002) The effects of prior light history on the suppression of melatonin by light in humans. J Pineal Res 33:198-203

74. Brainard GC, Hanifin JP (2004) The effects of light on human health and behavior: relevance to architectural lighting. Vienna: CIE x027:2-16

75. Cajochen C, Munch M, Kobialka S, et al. (2005) High sensitivity of human melatonin, alertness, thermoregulation and heart rate to short wavelength light. J Clin Endocrinol Metab 90:1311-1316

76. Lipson ED (1994) Action spectroscopy: methodology. In: Horspool WM, Song PS (eds) Organic Photochemistry and Photobiology. CRC Press, New York, 12571266

77. Matthes R, Sliney D, Didomenico S, Murray P, Phillips R, Wengraitis S (eds) (1999) Measurements of Optical Radiation Hazards. ICNIRP, Munchen, Germany, pp 1-762

78. Hrushesky WJM (2001) Melatonin cancer therapy. In: Bartsch C, Bartsch H, Blask DE, Cardinali DP, Hrushesky WJM, Mecke D (eds) The Pineal Gland and Cancer: Neuroendocrine Mechanisms in Malignancy. Springer-Verlag, Berlin, 476-508

79. Davis S, Mirick DK, Stevens RG (2001) Night shift work, light at night, and risk of breast cancer. J Natl Cancer Inst 93:1557-1562

80. Schernhammer ES, Laden F, Speizer FE, et al. (2001) Rotating night shifts and risk of breast cancer in women participating in the nurses' health study. J Natl Cancer Inst 93:1563-1568

81. Parkin DM, Laara E, Muir CS (1988) Estimates of worldwide frequency of sixteen major cancers in 1980. Int J Cancer 41:184-197

82. Stevens RG (1987) Electric power use and breast cancer: a hypothesis. Am J Epidemiol 125:556-561 
83. Stevens RG, Davis S (1996) The melatonin hypothesis: electric power and breast cancer. Environ Health Perspect 104:135-140

84. Blask DE, Dauchy RT, Sauer LA, Krause JA, Brainard GC (2003) Growth and fatty acid metabolism of human breast cancer (MCF-7) xenografts in nude rats: impact of constant light-induced nocturnal melatonin suppression. Breast Cancer Res Treat 79:313-320

85. Lewy AJ, Wehr TA, Goodwin FK, Newsome DA, Markey SP (1980) Light suppresses melatonin secretion in humans. Science 210:1267-1269

86. Blask DE, Brainard GC, McGowan T, Kesselring J (2004) Relationship Between Light and the Development and Growth of Internal Solid Cancers: A Review of Current Research and the Potential Implications for Lighting Practice. EPRI, Palo Alto, CA, and McClung Foundation, Conyers, GA, 1011162

87. Blask DE, Dauchy RT, Sauer LA, Krause JA, Brainard GC (2002) Light during darkness, melatonin suppression and cancer progression. Neuroendocrinol Lett 23:52-56

88. Dauchy RT, Blask DE, Brainard GC, et al. (2003) Low-intensity light exposure during animal room dark phase and alterations in tumor growth rate and metablolism in rats: a dose-response relationship. Contemp TopLab Anim Sci 42:101

89. Nanda K, Bastian LA, Schulz K (2002) Hormone replacement therapy and the risk of death from breast cancer: a systematic review. Am J Obstet Gynecol 186:325-334

90. Falkenberry SS, Legare RD (2002) Risk factors for breast cancer. Obstet Gynecol Clin North Am 29:159-172

91. MacMahon B, Cole P, Brown J (1973) Etiology of human breast cancer: a review. J Natl Cancer Inst 50:21-42

92. Kushi L, Giovannucci E (2002) Dietary fat and cancer. Amer J Med 113:63S-70S

93. Bianchini F, Kaaks R, Vainio H (2002) Overweight, obesity, and cancer risk. Lancet Oncol 3:565-574

94. Giovannucci E (2002) Modifiable risk factors for colon cancer. Gastroenterol Clin North Am 31:925-943

95. Ressel GW (2002) Amercan Cancer Society releases guidelines on nutrition and physical activity for cancer prevention. Am Fam Physician 66:1555, 1559-1560, 1562

96. White JD (2002) Cancer: current research in alternative therapies. Prim Care 29:379-392 